\title{
Pulmonary function in adolescents with mild idiopathic scoliosis
}

\author{
RJ SMYTH, KR CHAPMAN, TA WRIGHT, JS CRAWFORD, AS REBUCK \\ From the Divisions of Respiratory Medicine, Rehabilitation Medicine, and Orthopaedic Surgery, Toronto \\ Western Hospital, Toronto, Ontario, Canada
}

ABSTRACT Spirometric indices, lung volumes, maximum voluntary ventilation, and maximum inspiratory and expiratory pressures were measured in 44 adolescents with mild idiopathic scoliosis (spinal curvature less than $30^{\circ}$ ). All were symptom free, but six (13.6\%) showed a restrictive defect with forced vital capacity less than $80 \%$ of predicted. In 12 subjects $(27 \cdot 3 \%)$ maximum voluntary ventilation was reduced to less than $80 \%$ of predicted normal. Forced vital capacity was significantly correlated with maximum inspiratory pressure and with maximum expiratory pressure, measures of respiratory muscle strength, but was not related to the degree of thoracic curvature. When maximum inspiratory pressure and forced vital capacity were corrected for differences in body size these variables remained positively correlated, most significantly in the girls. These data indicate that ventilatory function may be impaired in mild, idiopathic scoliosis and that the force developed by the respiratory muscles is a more important determinant of this impairment than the radiologically determined degree of spinal curvature.

A reduction in vital capacity is a characteristic finding in patients with scoliosis. Total lung capacity may also be reduced, with residual volume usually found to be within normal limits. ${ }^{1}$ In moderate (curves of $30-50^{\circ}$ ) to severe (curves $>50^{\circ}$ ) scoliosis the reduction in vital capacity is related to the measured degree of spinal curvature,,$^{2}$ and there is necropsy evidence of both reduced alveolar size and number in the compressed lobes. ${ }^{3}$

As the measured ventilatory abnormalities can usually be related to the angle of spinal curvature it might be reasonable to assume that extrapulmonary lung restriction and altered chest wall mechanics are entirely responsible. There is, however, evidence of respiratory muscle weakness in patients with moderate to severe scoliosis, in particular of the postparalytic type. Cook et al and Gibson et al drew attention to the reduced maximum inspiratory and expiratory pressures that their patients were able to generate,${ }^{45}$ but these studies examined only patients with severe curvature, and few studies of scoliosis have dealt exclusively with the idiopathic form of

Address for reprint requests: Dr AS Rebuck, Division of Respiratory Medicine, Toronto Western Hospital, Toronto, Ontario M5T 2S8, Canada.

Accepted 5 June 1984 the disease. Accordingly, we examined the relation between forced vital capacity, maximum voluntary ventilation, and muscle force in a group of young patients with mild idiopathic scoliosis to evaluate the role of respiratory muscle weakness in their ventilatory impairment.

\section{Methods}

Forty four adolescents (12 boys, 32 girls) with idiopathic scoliosis were referred for study. A standing three foot anteroposterior chest radiograph was taken in each subject within two months after the start of the study, and the angle of the thoracic curvature was measured by the method of Cobb. ${ }^{6}$ Subjects with curves greater than $35^{\circ}$ were excluded. All subjects denied having cardiopulmonary symptoms, and none was receiving medical treatment at the time of the study. Informed parental consent was obtained for all participants.

Spirometric indices were recorded from the best of three maximum expiratory flow volume curves using a computerised system (Pulmonizer 525, Med-Science, St Louis, MO). Maximum voluntary ventilation was determined from a 12 second test.? All volumes were corrected to body temperature, pressure, and saturation. Non-deformed body height was estimated from arm span measurements 
using the regression equations of Linderholm and Lindgren. ${ }^{8}$ These calculated body heights were then used in the predictive equations of Weng and Levison." Functional residual capacity was determined by the helium dilution method. ${ }^{10}$ Maximum inspiratory and expiratory pressures were obtained by a modification of the method of Black and Hyatt," using a mercury filled $U$ tube (internal mouthpiece diameter $=2 \cdot 3 \mathrm{~cm}$ ). Each subject was instructed to exhale to residual volume or inhale to total lung capacity, before attempting to inhale/ exhale maximally into the mouthpiece. Each subject was also instructed to avoid collapsing the cheeks during measurement of maximum inspiratory pressure. If inspection showed air leakage around the lips during the manoeuvre the measurement was repeated until technically satisfactory. The value was recorded as the level of the mercury column that was sustained for 2-3 seconds. Each measurement was performed at least twice and the highest value was recorded and expressed in $\mathrm{cm}_{2} \mathrm{O}$.

Relations between the measured variables were sought by single and multiple linear regression analyses. Forced vital capacity and maximum voluntary ventilation were expressed both as absolute values and as percentages of predicted normal values. Maximum inspiratory pressure and maximum expiratory pressure were also expressed both in absolute terms and as a percentage of normal values using data obtained in this laboratory for healthy adolescent subjects aged 13 to 18 (mean (SD), for boys: maximum inspiratory pressure $=106.9(26 \cdot 2)$ $\mathrm{cm} \mathrm{H}_{2} \mathrm{O}$; maximum expiratory pressure $=114 \cdot 3$ $(35.2) \mathrm{cm} \mathrm{H}_{2} \mathrm{O}$; for girls maximum inspiratory pressure $=76.3(25.4) \mathrm{cm} \mathrm{H}_{2} \mathrm{O}$; maximum expiratory pressure $\left.=85.7(21 \cdot 8) \mathrm{cm} \mathrm{H}_{2} \mathrm{O}\right)$. Significance was reported at the 0.05 level.

\section{Results}

Table 1 shows the physical characteristics of the subjects and their pulmonary function data. The mean (SD) forced vital capacity (expressed as a percentage of the predicted value) was $94.3(14.6) \%$. Six
Table 1 Physical characteristics of subjects. The figures are mean values (SD)

\begin{tabular}{|c|c|c|c|}
\hline & $\begin{array}{l}\text { Males } \\
(n=12)\end{array}$ & $\begin{array}{l}\text { Females } \\
(n=32)\end{array}$ & $\begin{array}{l}\text { Total } \\
(n=44)\end{array}$ \\
\hline $\begin{array}{l}\text { Age (years) } \\
\text { Arm span }(\mathrm{cm}) \\
\text { Weight }(\mathrm{kg}) \\
\text { Curve ( }\left(^{\circ}\right) \\
\text { FVC (l) } \\
\text { Proportion of predicted }\end{array}$ & $\begin{array}{c}14 \cdot 7(3 \cdot 5) \\
173 \cdot 0(17 \cdot 5) \\
59 \cdot 3(17 \cdot 8) \\
12 \cdot 1(7 \cdot 5) \\
4 \cdot 7(1 \cdot 3)\end{array}$ & $\begin{array}{r}17 \cdot 5(4 \cdot 9) \\
165 \cdot 4(7 \cdot 8) \\
55 \cdot 3(8 \cdot 3) \\
18 \cdot 9(9 \cdot 3) \\
3 \cdot 6(6 \cdot 3)\end{array}$ & $\begin{array}{r}16 \cdot 7(4 \cdot 7) \\
167 \cdot 5(11 \cdot 6) \\
56 \cdot 4(11 \cdot 7) \\
17 \cdot 0(9 \cdot 3) \\
3.9(9 \cdot 7)\end{array}$ \\
\hline $\begin{array}{l}\text { FVC }(\%) \\
\text { TLC (I) }\end{array}$ & $\begin{array}{c}94.8(15.4) \\
5.7(1.7)\end{array}$ & $\begin{array}{c}94 \cdot 2(14 \cdot 5) \\
4 \cdot 7(7 \cdot 8)\end{array}$ & $\begin{array}{c}94 \cdot 3(14 \cdot 6) \\
4 \cdot 9(1 \cdot 2)\end{array}$ \\
\hline $\begin{array}{l}\text { Proportion of predicted } \\
\operatorname{TLC}(\%) \\
\operatorname{MVV}\left(1 \mathrm{~min}^{-1}\right)\end{array}$ & $\begin{array}{r}89.2(15 \cdot 1) \\
129.5(44.4)\end{array}$ & $\begin{array}{r}88 \cdot 2(13 \cdot 1) \\
103 \cdot 1(24 \cdot 0)\end{array}$ & $\begin{array}{r}88.4(13.5) \\
110.3(32.6)\end{array}$ \\
\hline $\begin{array}{l}\text { Proportion of predicted } \\
\operatorname{MVV~}(\%) \\
\operatorname{MIP}\left(\mathrm{cm} \mathrm{H} \mathrm{H}_{2} \mathrm{O}\right) \\
\operatorname{MEP}\left(\mathrm{cm} \mathrm{H} \mathrm{H}_{2} \mathrm{O}\right)\end{array}$ & $\begin{array}{r}82.7(14.8) \\
95.9(29.8) \\
105.9(41.4)\end{array}$ & $\begin{array}{l}89.4(21 \cdot 7) \\
69.3(28 \cdot 1) \\
69.7(28.5)\end{array}$ & $\begin{array}{l}87.5(20.1) \\
76.6(30.7) \\
79.5(35.9)\end{array}$ \\
\hline
\end{tabular}

subjects had a forced vital capacity of less than $80 \%$ Ф of predicted normal $(74.7(4 \cdot 1) \%)$; using the $95 \% \vec{\bullet}$ confidence limits derived from the standard devia- $\infty$ tion of the predictive equation, five subjects had subnormal vital capacities. Mean values for maximal inspiratory and expiratory pressure were within normal limits established in our laboratory ${ }^{12}$ and the normal values for adolescents reported by Leech et al. ${ }^{13}$

There were significant linear relations between $\overline{\overline{0}}$ forced vital capacity and maximum inspiratory pressure or maximum expiratory pressure, as table 2 . shows. To verify that these relations were not simply a consequence of different body sizes among subjects, forced vital capacity ( $\%$ predicted) was com- $\frac{O}{Q}$ pared with maximum inspiratory pressure and maximum expiratory pressure ( $\%$ predicted) for all sub- $\frac{0}{3}$ jects as well as separately for boys and girls (table 3). Maximum inspiratory pressure (\% predicted) and forced vital capacity (\% predicted) were positively correlated for all subjects, this correlation? reaching significance for girls $(r=0.40, p<0.05)$ 응 A weak negative correlation between these variables was not significant for the small number (12) N

Table 2 Summary of results of regression analysis

\begin{tabular}{|c|c|c|c|c|}
\hline & \multicolumn{2}{|c|}{ Forced vital capacity $(l)$} & \multicolumn{2}{|c|}{ Maximum voluntary ventilation (l/min) } \\
\hline & $r$ & $p$ & $r$ & $p$ \\
\hline $\begin{array}{l}\text { Maximum inspiratory pressure }\left(\mathrm{cm} \mathrm{H}_{2} \mathrm{O}\right) \\
\text { Maximum expiratory pressure }\left(\mathrm{cm} \mathrm{H}_{2} \mathrm{O}\right) \\
\text { Curve }\left(^{\circ}\right) \\
\text { Forced vital capacity }(\mathrm{l})\end{array}$ & $\begin{array}{l}0.37 \\
0.32 \\
0 \cdot 14\end{array}$ & $\begin{array}{r}<0.02 \\
<0.05 \\
0.38\end{array}$ & $\begin{array}{l}0.44 \\
0.36 \\
0.03 \\
0.82\end{array}$ & $\begin{array}{c}<0.005 \\
<0.02 \\
0.84 \\
<0.001\end{array}$ \\
\hline
\end{tabular}


Table 3 Results of regression analysis using variables corrected for body size

\begin{tabular}{|c|c|c|c|}
\hline & \multicolumn{3}{|c|}{ Forced vital capacity (\% predicted) } \\
\hline & Males & Females & Total \\
\hline $\begin{array}{l}\text { Maximum inspiratory pressure } \\
\text { (\% predicted) }\end{array}$ & $\begin{array}{l}r=-0.37 \\
p=0.25\end{array}$ & $\begin{array}{l}r=0.40 \\
p<0.05\end{array}$ & $\begin{array}{l}r=0.23 \\
p=0.14\end{array}$ \\
\hline $\begin{array}{l}\text { Maximum expiratory pressure } \\
\text { (\% predicted) }\end{array}$ & $\begin{array}{l}r=0.02 \\
p=0.96\end{array}$ & $\begin{array}{l}r=0 \cdot 24 \\
p=0 \cdot 18\end{array}$ & $\begin{array}{l}r=0.19 \\
p=0.22\end{array}$ \\
\hline
\end{tabular}

of boys studied. Maximum expiratory pressure (\% predicted) and forced vital capacity (\% predicted) were positively but not significantly correlated among all subject groups. There was no significant regression relation between forced vital capacity (l), or forced vital capacity (\% predicted), and the degree of thoracic curvature.

Maximum voluntary ventilation was less than $80 \%$ of predicted in 12 subjects (three of whom also showed forced vital capacity less than $80 \%$ of predicted) and was significantly related to forced vital capacity $(p<0.001)$, maximum inspiratory pressure $(\mathrm{p}<0.005)$, and maximum expiratory pressure $(\mathrm{p}<$ $0 \cdot 02)$. Multiple regression analysis of maximum voluntary ventilation versus these variables showed that forced vital capacity was the best single predictive variable and that the regression relation was not significantly improved by the addition of either maximum inspiratory pressure or maximum expiratory pressure to the regression model.

Hence the results indicated that the reduced vital capacity that may be found in patients with mild scoliosis is not determined by their degree of curvature. A more important determinant appeared to be respiratory muscle strength.

\section{Discussion}

Whereas studies of moderate to severe scoliosis have produced a large body of information regarding pulmonary function in severe forms of the disease, the respiratory abnormalities of mild scoliosis have received little attention; the few studies that have focused on these abnormalities have measured only spirometric indices. The present study examined a group of patients with mild, asymptomatic scoliosis, and observations were extended to include a measure of respiratory muscle strength. Our data showed that adolescents with mild idiopathic scoliosis may have reduced lung volumes in the presence of minimal lateral curvatures, a finding that paralleled observations in patients with scoliosis with more severe spinal deformities. In contrast with studies of severe idiopathic scoliosis, however, the reduced vital capacity of mild scoliosis was better correlated with measures of respiratory muscle strength than with the degree of spinal curvature.

A reduction in vital capacity in severe scoliosis was first reported by Schneevegt in 1854, an observation confirmed subsequently by numerous investigators. Kafer described several possible mechanisms for the effects of scoliosis on lung volumes. ${ }^{14}$ They included abnormal development of the thorax, the increased elastic force of the respiratory system, which opposes the muscle forces during maximum inspiration and expiration, and the effects of the deformity on the development of inspiratory or expiratory muscle force. She noted, however, that there were insufficient physiological data to determine the relative importance of these mechanisms. Numerous studies have shown a strong correlation between the degree of thoracic curvature and reductions in vital capacity in severe scoliosis. Other studies of patients with idiopathic scoliosis have shown correlations between the compliance of the total respiratory system and the degreee of curvature. ${ }^{15}$ Maximum respiratory pressures as an index of respiratory muscle strength have been found to be reduced in severe idiopathic scoliosis. ${ }^{4}$ The correlation between respiratory muscle strength and reduction in lung volume is stronger, however, in neuropathic scoliosis, a form of the disorder in which the relation between respiratory system compliance and angle of curvature is not significant. ${ }^{14}$ This has suggested an important role for respiratory muscle weakness in the development of lung restriction in neuropathic forms of the disease. Our data in mild idiopathic scoliosis paralleled previous findings in neuropathic scoliosis by showing that forced vital capacity was better related to respiratory muscle power than to the degree of spinal deformity. Thus a decrement in respiratory muscle strength may be an important clinical finding in both forms of the disease.

Our results agreed with those of Jones et al,$^{16}$ who studied adolescent girls with idiopathic scoliosis of mild, moderate, and severe degree, using chest strapping, and found that mechanical impediment alone did not account for the reduced vital capacity of idiopathic scoliosis. Jones $e t$ al also found a reduction in maximum inspiratory and expiratory mouth pressures in patients compared with control subjects and suggested that the respiratory muscles were at a mechanical disadvantage in this disorder. Also in agreement with Jones $e t$ al, we observed a reduction in the ratio of maximum expiratory pressure to maximum inspiratory pressure in our patients compared with the controls $(1.01 v 1.12)$ but, in contrast, we found that maximum inspiratory pressure correlated best with the reduction in vital capacity. This correlation between vital capacity and maximum 
inspiratory pressure is more physiologically appealing in view of the known importance of inspiratory muscle strength in the determination of vital capacity. ${ }^{7}$ This relation between maximum inspiratory pressure and forced vital capacity probably cannot be accounted for solely by differences in body size among subjects; a similar positive association was observed when these variables were expressed as a percentage of predicted normal values. The lack of correlation between lung volume and spinal curvature in our study, however, probably reflected in part the inadequacy of lateral curvature measurements alone as a complete description of thoracic deformity.

Kafer reported an inverse relation between the angle of curvature and body weight in idiopathic scoliosis. ${ }^{14}$ She concluded that body growth may be impaired in scoliosis by a mechanism as yet to be determined. In our study there was a significant correlation between body weight and maximum inspiratory pressure $(r=0.42, p<0.005)$. Reduced maximum inspiratory values may therefore result from growth impairment seen in idiopathic scoliosis, including perhaps a decreased muscle mass. No primary metabolic or muscular abnormality has been identified as the cause of idiopathic scoliosis, although some evidence suggests that the disease is genetically linked. ${ }^{17}$

Our data did not allow us to determine whether reduced respiratory muscle strength is a primary mechanism in the development of idiopathic scoliosis or merely secondary to other pathogenetic factors. Our observations should, however, direct attention to the importance of the pathophysiological derangements seen in idiopathic scoliosis. Whatever primary abnormality or abnormalities underlie idiopathic scoliosis, it may be useful to consider the role of the respiratory muscles when developing treatment strategies to improve, or at least prevent deterioration of, pulmonary function in this condition.

We thank Ms C MacHattie for her technical help and Ms M T Berk for her help with preparing the manuscript.

\section{References}

1 Weber B, Smith JP, Briscoe WA, Friedman SA, King TKC. Pulmonary function in asymptomatic adolescents with idiopathic scoliosis. Am Rev Respir Dis 1975;3:389-97.

2 Mankin HJ, Graham JJ, Schack J. Cardiopulmonary function in mild and moderate idiopathic scoliosis. $J$ Bone Joint Surg [Am] 1964;46:53-62.

3 Godfrey S. Respiratory and cardiovascular consequences of scoliosis. Respiration 1970;27 (suppl):67-70.

4 Cook CD, Barrie H, DeForest SA, Welliesen PJ. Pulmonary physiology in children. III. Lung volumes, mechanics of respiration and respiratory muscle strength in scoliosis. Pediatrics 1960;25:766-74.

5 Gibson GJ, Pride NB, Newsom-Davis J, Loh LC. Pulmonary mechanics in patients with respiratory muscle weakness. Am Rev Respir Dis 1977;115:389-95.

6 Cobb JR. Outline for the study of scoliosis. Instr Course Lect 1948;5:261-75. (Issued by American Academy of Orthopaedic Surgeons.)

7 Cotes JE. Lung function: assessment and application in medicine. 4th ed. Oxford: Blackwell Scientific Publications, 1979.

8 Linderholm $\mathrm{H}$, Lindgren U. Prediction of spirometric values in patients with scoliosis. Acta Orthop Scand 1978;49:469-74.

9 Weng TR, Levison H. Standards of pulmonary function in children. Am Rev Respir Dis 1969;99:879.

10 Holmgren A. Determination of functional residual capacity by means of the helium dilution method. Scand J Clin Invest 1954;6:131-6.

11 Black LF, Hyatt RE. Maximal respiratory pressures: normal values and relationship to age and sex. $A m R e v$ Respir Dis 1969;99:696-702.

12 Smyth RJ, Chapman KR, Rebuck AS. Maximal inspiratory and expiratory pressures in adolescents: normal values. Chest 1984;86:568-72.

13 Leech JA, Ghezzo H, Stevens D, Becklake MR. Respiratory pressures and function in young adults. Am Rev Respir Dis 1983;128:17-23.

14 Kafer ER. Respiratory and cardiovascular functions in scoliosis. Bull Eur Physiopathol Respir 1977;13:299 321.

15 Kafer ER, Idiopathic scoliosis. Gas exchange and the age dependence of arterial blood gases. $J$ Clin Invest 1976;58:825-33.

16 Jones RS, Kennedy JD, Hasham F, Owen R, Taylor JF. Mechanical inefficiency of the thoracic cage in scoliosis. Thorax 1981;36:456-61.

17 Wynne-Davis R. Familial (idiopathic) scoliosis. J Bone Joint Surg [Br] 1968;50:24-30. 